\title{
CAMINHOS LEGISLATIVOS E EDUCACIONAIS INCLUSIVOS PERCORRIDOS POR PESSOAS COM DEFICIÊNCIA NO BRASIL
}

\section{LEGISLATIVE AND EDUCATIONAL PATHWAYS INCLUDED BY PEOPLE WITH DISABILITIES IN BRAZIL}

\author{
Tatiane Oliveira Santos Pereira Abreu ${ }^{60}$
}

\begin{abstract}
Resumo
Historicamente as pessoas com deficiência ou que fossem consideradas fora do padrão de normalidade eram marginalizadas e excluídas socialmente. Mediante a esse contexto, considerou-se realizar uma pesquisa que abarcasse um breve relato sobre a (in)visibilidade desses sujeitos e a exposição dos principais documentos que regem a educação especial no Brasil. Para tanto, utilizou-se de revisão bibliográfica de documentos com a temática de educação especial e inclusiva. Verificamos que ocorreram avanços no que tange à educação especial no Brasil, tais como a matrícula em sala de aula regular e o acesso ao atendimento educacional especializado. Contudo, há de se reconhecer que ainda não possuímos uma escola inclusiva de fato no Brasil. Embora estejamos a caminho dela e tenhamos leis, normas e documentos que garantam o acesso e a permanência desses alunos nesses espaços, ainda existem inúmeras barreiras a serem superadas.
\end{abstract}

Palavras-chave: Educação Especial. Inclusão educacional. Legislação. Pessoa com deficiência.

\begin{abstract}
Historically, people with disabilities or who were considered to be out of the normal range were marginalized and socially excluded. In this context, it was considered to carry out a research that covered a brief report on the (in) visibility of these subjects and the exposure of the main documents that govern special education in Brazil. For that, we used a bibliographic review of documents with the theme of special and inclusive education. We found that advances have been made in relation to special education in Brazil, such as enrollment in a regular classroom and access to specialized educational assistance. However, it must be recognized that we do not yet have a de facto inclusive school in Brazil. Although we are on the way to it and have laws, rules and documents that guarantee the access and permanence of these students in these spaces, there are still numerous barriers to be overcome.
\end{abstract}

Keywords: Special education. Educational inclusion. Legislation. Disabled person.

\footnotetext{
${ }^{60}$ Graduanda em Pedagogia. Faculdade de Formação de Professores (FFP-UERJ). E-mail: tatyolivabreu@gmail.com . ORCID: https://orcid.org/0000-0002-7198-7936.
} 


\section{RevistAleph}

\section{Introdução}

As reflexões e diálogos que são tecidos ao longo deste trabalho são fruto da trajetória acadêmica que venho percorrendo até o momento, como estudante das disciplinas de educação especial (obrigatória/ optativa); a realização de monitoria (na disciplina de educação especial desde 2019), no curso de Pedagogia da Faculdade de Formação de Professores (FFP- UERJ); a atuação como voluntária em projetos de extensão, cujas temáticas são: autismo (Os efeitos da Terapia Assistida por Cães no Desenvolvimento Global de Crianças com Transtorno do Espectro Autista - FFP/UERJ) e surdez (Ensino de surdo sob a perspectiva bilíngue - UFF); pela participação em um grupo de pesquisa sobre cães e autismo (Grupo de Estudos e Pesquisas em Autismo e Intervenções Assistidas por Cães - GEPAC/ UERJ). Tais encontros contribuíram para as concepções de educação especial e inclusiva que possuo hoje.

O caminho metodológico realizado tem como base a revisão bibliográfica da legislação no campo, artigos e livros com a temática de educação especial e inclusiva.

O trabalho em questão está estruturado em um breve relato sobre a (in)visibilidade das pessoas com deficiência ao longo da história, a trajetória brasileira da inclusão escolar das pessoas com deficiência e considerações finais.

Quanto aos diálogos e reflexões, os seguintes autores foram usados como embasamento: (i) Cabral (2020), Matozzoto (2000, 2008 e 2011), Silva (2012) e Menezes (2015) que tratam das questões relacionadas ao papel histórico e social de pessoas com deficiências; (ii) Ortega (2009) e Rios (2017) que contribuíram sobre as questões relativas ao empoderamento e autoadvocacia desses sujeitos; (iii) Mantoan (2003) que enfoca mais diretamente as questões relacionadas à inclusão escolar; (iv) Moraes (2017) que expõe as reflexões sobre Plano Nacional de Educação com recorte para educação especial e (v) Silva (2012) que enfoca os direitos sociais e educacionais de pessoas com deficiência.

Os documentos referenciais da educação especial utilizados foram: a Declaração Mundial sobre Educação para Todos (1990), a Declaração de Salamanca (1994), as Diretrizes Nacionais para a Educação Especial na Educação Básica (2006), a Política Nacional de Educação Especial na Perspectiva da Educação Inclusiva (2008), o 


\title{
RevistAleph
}

Manual de Orientação do Programa de Implantação de Salas de Recursos Multifuncionais (2010) e do Documento Orientador do Programa Implantação de Salas de Recursos Multifuncionais (2013).

As leis que embasaram a realização dos estudos relativos à legislação da educação especial foram as de números: 4.024/61, 7.853/89, 8.069/90, 9.394/96, 10.436/02, 12.764/12, 13.005/14, 13.146/15; os Decretos de números: 3.298/99 e no 5.626/05; além das Resoluções de números: 4/09 e 4/10.

\section{Breve relato sobre a (in)visibilidade das pessoas com deficiência ao longo da história}

\begin{abstract}
A antonímia da diferença não é a igualdade, mas a singularidade constituída pelas identidades que, por serem múltiplas, quando se deparam umas diante às outras no âmbito de uma sociedade, demarcam as suas diferenças (CABRAL, 2018, p. 11).
\end{abstract}

Ao longo da história as pessoas com deficiência, ou que fossem consideradas fora do padrão de normalidade, eram afastadas e excluídas do convívio social, enfrentando os mais variados tipos de violência.

Segundo pesquisadores e estudiosos, existem poucos registros históricos sobre a deficiência na antiguidade. No entanto, os poucos registros que existem, relatam que as pessoas com deficiências recebiam tratamentos desumanos e viviam excluídas de tal forma que, sequer, eram consideradas seres humanos (Cabral, 2020).

Na Idade Média as concepções sobre a deficiência sofreram algumas mudanças em decorrência de alguns movimentos sociais eurocêntricos da época. O contexto no qual tais concepções se desenvolveram era rural, fortemente influenciado pelo cunho religioso, tendo como principal perspectiva o cristianismo, em que se dava às pessoas com deficiência tratamentos completamente antagônicos: ora de maus-tratos, ora de supervalorização.

Cabral (2020, p. 20) salienta:

[...] a partir de meados dos séculos XIII e XIV, com a ideia de que uma pessoa com deficiência poderia ser a imagem e semelhança de Deus, as pessoas começaram a não eliminar essas pessoas, como na antiguidade, e passaram a super protegê-las, contribuindo com a construção de uma visão caritativa e assistencialista. 


\section{RevistAleph}

No entanto, também existia no cristianismo da época, a vertente de que a pessoa teria deficiência devido a algum castigo divino, relacionando tais indivíduos com

algo maligno e tendo como consequência os maus-tratos.

No

período renascentista a deficiência passa a ser associada à patologia, passando as pessoas com deficiência a terem tratamento assistido por médicos. A partir desse período e por meio do aprofundamento dos estudos desses especialistas, assim como também dos profissionais da educação, começaram a se desenvolver pensamentos sobre a educação desses sujeitos. Os principais precursores da educação especial deste período, segundo Cabral (2020, p:21), foram: “[...] Philippe Pinel (1745-1826), Jean Marc Gaspard Itard (1775-1838), Édouard Séguin (1812-1880) e Maria Montessori (18701952)".

Em 1789 com a Revolução Francesa surgiram alguns movimentos que também tinham como integrantes pessoas com deficiências que reivindicaram e conseguiram, aos poucos, acesso à educação mesmo que em escolas ou instituições especiais (CABRAL, 2020).

As duas grandes guerras mundiais ocorridas no século XX ocasionaram a alguns dos soldados sobreviventes a mutilação de seus corpos e como consequência, surgiram discursos sobre a igualdade e desigualdade, resultando em 1948 a Declaração Universal dos Direitos Humanos. A partir deste período surgiram diversos documentos que objetivavam a proteção e a dignidade das pessoas com deficiências (SILVA, 2012). Matozzoto (2011) relata que a partir de 1980 a inclusão tem se consagrado no mundo ocidental através dos movimentos sociais e políticos. Um dos lemas mais conhecidos e adotados pelos militantes do movimento em prol dos deficientes desde 1970 era: "nada sobre nós, sem nós" - que sintetiza as principais questões reivindicadas por esses militantes. Rios (2017, p. 215) destaca:

Reivindicam-se não apenas direitos e benefícios no âmbito social, mas, acima de tudo, o reconhecimento das pessoas com deficiência como sujeitos livres e autônomos, capazes de se posicionar e participar na tomada de decisões em distintas esferas sociais sem a interferência de terceiros $[\ldots]$. 


\section{RevistAleph}

Ortega (2009, p. 68) destaca ainda que "[...]basicamente, o modelo social da deficiência surge como alternativa ao modelo hegemônico médico-individual com sua ênfase no diagnóstico e que constrói o indivíduo deficiente como sujeito dependente [...]."

Para os pesquisadores desses movimentos a afirmação de identidade desses indivíduos se constitui como sendo "[...]um compromisso coletivo e político de protesto contra as barreiras sociais incapacitantes encaradas pelos indivíduos com algum tipo de lesão, como de uma transformação da identidade pessoal vivenciada com orgulho [...]" (ORTEGA, 2009, p. 69).

Sassaki

(2003) aponta que os cuidados com a linguagem também se fazem necessários para construção de uma sociedade inclusiva, para tanto é importante ressaltar a mudança quanto a nomenclatura para fazer referência às pessoas com deficiência. Como exemplo de alguns dos termos que já foram usados temos: inválidos, incapacitados, defeituosos, excepcionais, deficientes, portadores de deficiência, pessoas com necessidades especiais. Atualmente o termo usado é: pessoa com deficiência (SASSAKI, 2014).

O termo pessoa com deficiência usado na contemporaneidade marca a passagem da visão da deficiência como algo patológico de cunho assistencialista, ficando assim claro que a deficiência não está no indivíduo, mas na relação entre o mesmo com o meio em que vive, nos casos em que esse meio não ofereça suporte para o pleno desenvolvimento e participação em sociedade desses sujeitos, este ambiente torna-se deficiente.

\section{Trajetória brasileira da inclusão escolar das pessoas com deficiência}

"A inclusão acontece quando se aprende com as diferenças e não com as igualdades." (Paulo Freire)

No Brasil as duas primeiras escolas voltadas para o ensino de educandos com necessidades especiais surgiram ainda no período imperial. A primeira, em 1854, cujo nome era Imperial Instituto dos Meninos Cegos (atual Instituto Benjamin Constant IBC), tinha como objetivo o ensino de meninos cegos e exerce, até os dias atuais, a 


\section{RevistAleph}

escolarização de pessoas com deficiência visual. Já a segunda escola foi criada em 1857 e recebeu o nome de Instituto Nacional de Surdos-Mudos (atual Instituto Nacional de Educação de Surdos - INES).

Na sequência, em 1926, foi fundado o Instituto Pestalozzi, cujo objetivo inicial era o atendimento de pessoas com deficiência mental. Em 1945 a instituição passa a realizar também o atendimento de pessoas superdotadas ${ }^{61}$ por Helena Antipoff. ${ }^{62}$

As instituições voltadas para o ensino de pessoas com deficiências no âmbito nacional começaram a surgir após a criação da Declaração Universal dos Direitos Humanos ${ }^{63}$, fundadas pelos movimentos de pessoas com deficiências, pais e familiares. Como exemplo podemos citar a Associação de Pais e Amigos dos Excepcionais (APAE), fundada em 1954.

Dentre os documentos oficiais nacionais temos a Lei de Diretrizes e Bases da Educação (lei $n^{\circ}$ 4.024, de 1961) que em seus artigos 88 e 89 cita a educação de excepcionais (termo usado na época para definir as pessoas com deficiência), reafirmando o direito à educação desses indivíduos.

A Constituição Federal de 1988, foi um dos grandes marcos no que se refere à escolarização de pessoas com deficiência. Em seu artigo 205 garante a todos o direito à educação, sendo a oferta dever do Estado e da família, com o objetivo do pleno desenvolvimento do educando, preparando-o para o exercício da cidadania e sua qualificação para o trabalho. No inciso III do artigo 208 da CF/88 garante o direito ao Atendimento Educacional Especializado (AEE), preferencialmente na rede regular de ensino. Ademais, no inciso II do artigo 27 garante a:

[...]criação de programas de prevenção e atendimento especializado para as pessoas portadoras de deficiência física, sensorial ou mental,

\footnotetext{
61 “[...]Alunos com altas habilidades/superdotação demonstram potencial elevado em qualquer uma das seguintes áreas, isoladas ou combinadas: intelectual, acadêmica, liderança, psicomotricidade e artes. Também apresentam elevada criatividade, grande envolvimento na aprendizagem e realização de tarefas em áreas de seu interesse. [...]" (BRASIL, 2008, s/p).

62 Psicóloga e educadora russa, pioneira da educação especial no Brasil.

63 A Declaração Universal dos Direitos Humanos de 1948 em seu artigo 26, fala sobre o direito à educação para todos, devendo ser gratuita e o ensino fundamental obrigatório, a partir deste documento surgiram diversos outros.
} 


\section{RevistAleph}

bem como de integração social do adolescente e do jovem portador de deficiência, mediante $o$ treinamento para $o$ trabalho e a convivência, e a facilitação do acesso aos bens e serviços coletivos, com a eliminação de obstáculos arquitetônicos e de todas as formas de discriminação. (Redação dada pela Emenda Constitucional no 65, de 2010) (BRASIL, 1988).

A Lei Federal n.ำ 7.853 de 1989 em seu artigo $2^{\circ}$ assegura às “pessoas portadoras de deficiências" o direito à educação, à saúde, dentre outros. No tocante a educação, a referida lei estabelece:

[...] I - na área da educação:

a) a inclusão, no sistema educacional, da Educação Especial como modalidade educativa que abranja a educação precoce, a préescolar, as de 10 e 20 graus, a supletiva, a habilitação e reabilitação profissionais, com currículos, etapas e exigências de diplomação próprios;

b) $a$ inserção, no referido sistema educacional, das escolas especiais, privadas e públicas;

c) $a$ oferta, obrigatória e gratuita, da Educação Especial em estabelecimento público de ensino;

d) o oferecimento obrigatório de programas de Educação Especial a nível pré-escolar, em unidades hospitalares e congêneres nas quais estejam internados, por prazo igual ou superior a 1 (um) ano, educandos portadores de deficiência;

e) 0 acesso de alunos portadores de deficiência aos benefícios conferidos aos demais educandos, inclusive material escolar, merenda escolar e bolsas de estudo;

f) a matrícula compulsória em cursos regulares de estabelecimentos públicos e particulares de pessoas portadoras de deficiência capazes de se integrarem no sistema regular de ensino [...](BRASIL, 1989).

Os anos 90 foram marcados por eventos mundiais com as temáticas da educação para todos e da educação especial. Destacam-se a Conferência Mundial sobre Educação para Todos, em Jomtien, Tailândia, em 1990 e a Conferência Mundial sobre Necessidades Educacionais Especiais, 1994, que ocorreu em Salamanca na Espanha. Em ambas as conferências o Brasil é signatário.

Na Conferência Mundial sobre Educação para Todos (1990) foi aprovada a "Declaração Mundial sobre Educação para Todos" que diz que todos têm direito à educação e que as necessidades básicas de aprendizagem devem ser supridas.

A Conferência Mundial sobre Necessidades Educacionais Especiais (1994), aprovou a Declaração de Salamanca que estabelece princípios e normas acerca da educação especial e inclusiva de 


\section{RevistAleph}

estudantes com necessidades educacionais especiais, garantindo o direito e acesso à escola regular, com uma pedagogia centrada no educando para o atendimento de suas demandas. Este documento aponta que o princípio fundamental que constitui uma escola inclusiva é a aprendizagem coletiva de todas as crianças, além do dever de assegurar a todos uma educação de qualidade ofertando, quando necessário, um currículo adaptado e flexível para a promoção do desenvolvimento desses indivíduos.

Matozzoto (2000, p. 99) salienta

que

[...] os princípios e propostas contidos nessa Declaração de 1994 refletem a consolidação de anseios de grupos organizados, com renovado poder de pressão sobre os órgãos governamentais e fortalecimento da conviç̧ão da importância e urgência de transformações sócio-educacionais compatíveis com o imprescindível respeito à diversidade do ser humano.

Em suma, tais documentos são marcos históricos referenciais para a construção de legislações e políticas públicas na área da educação especial e inclusiva, vigentes atualmente, por terem defendido a perspectiva inclusiva de que todos têm direito à educação.

No

cenário nacional a Lei Federal no. 8.069/90 intitulada como Estatuto da Criança e do Adolescente (ECA), em seu artigo 54, inciso III, estabelece como dever do Estado o "Atendimento Educacional Especializado aos portadores de deficiência, preferencialmente na rede regular de ensino" (BRASIL, 1990).

A Lei de Diretrizes e Bases da Educação (LDB n‥ 9.394/96), em seu Artigo 4으, inciso III, assegura o oferecimento gratuito do Atendimento Educacional Especializado aos educandos com necessidades especiais, especificando a quem é destinado esse atendimento (pessoas com deficiências, transtornos globais do desenvolvimento e altas habilidades ou superdotação). Cabe ressaltar que a LDB trata especificamente sobre as questões relacionadas à escolarização de educandos com necessidades educacionais especiais no Capítulo V em seus artigos 58, 59, 60.

Especificamente o artigo 58 define a educação especial como uma modalidade de ensino que deve ser ofertada em todos os segmentos da educação básica através dos 


\section{RevistAleph}

atendimentos de apoio especializado. Nos casos em que não for possível a integração desses estudantes em classes regulares em virtude de suas condições específicas, o atendimento educacional deverá ser feito em classes, escolas ou serviços especializados.

Já o artigo 59 salienta que os sistemas de ensino devem garantir aos educandos com necessidades educativas específicas a adaptação de currículo, métodos, técnicas, recursos educativos e organização específicos para atender suas especificidades. Garante também professores que tenham especialização para o atendimento especializado, podendo ser em nível médio ou superior, visando a integração desses educandos às classes regulares. Garante também o acesso igualitário aos benefícios dos programas sociais suplementares ofertados aos diferentes segmentos da educação básica.

O Decreto Federal no

3.298/99 estabelece em sua seção II, artigo 24, o direito à educação pública e gratuita sendo realizada, preferencialmente, na rede regular de ensino, assim como também confere aos educandos com necessidades educacionais especiais os mesmos direitos e benefícios que aos demais estudantes: a oferta de material escolar, transporte, merenda escolar e bolsas de estudo.

O Decreto ainda destaca que o processo de aprendizagem na educação especial deva desenvolver-se de forma flexível, dinâmica e individualizada, garantindo sua presença em todos os níveis e modalidades de escolaridade. Ademais, garantir a inclusão desses indivíduos nos sistemas educacionais escolares ou/e instituições especializadas públicas ou privadas; e assegurar o atendimento especializado para estudantes com deficiências mesmo que estejam internados em hospitais.

O documento ressalta também que o início da escolarização ocorra de 0 (zero) anos de idade na educação infantil até o oferecimento do ensino superior, prevendo em seu artigo 27 adaptações em relação às provas e apoio educacional quando necessário - tais adaptações devem ser solicitadas com antecedência pelo aluno, incluindo o tempo adicional para fazer as provas conforme a sua deficiência. Convém destacar que a Resolução CNE/CEB no 2/2001 sobre as Diretrizes Nacionais para a Educação Especial na Educação Básica amplia 


\section{RevistAleph}

[...] o caráter da educação especial para realizar o atendimento educacional especializado complementar ou suplementar a escolarização, porém, ao admitir a possibilidade de substituir o ensino regular, não potencializa a adoção de uma política de educação inclusiva na rede pública de ensino prevista no seu artigo 2으 (BRASIL, $2008, s / p)$.

Especialmente sobre a educação para surdos, em 2002 a forma gestual de comunicação usada pela maioria dos surdos, a Libras, passou a ser reconhecida como uma língua pela Lei no $10.436 / 02$, por meio de seu art.4ํㅡ e estabeleceu que os sistemas educacionais nas esferas federais, estaduais, municipais e pelo Distrito Federal devem garantir sua inclusão na formação de Educação Especial, para os cursos de Fonoaudiologia e de formação de professores a nível médio e superior, como disciplina optativa.

especificamente sobre a educação para deficientes visuais, a Portaria no 2.678 de 2002 em seu artigo $1^{\circ}$ "aprova o projeto da Grafia Braille para a Língua Portuguesa em todas as modalidades de ensino bem como a produção, em todo o território nacional" (BRASIL, 2006).

A partir de 2005 ocorre a criação dos Núcleos de Atividade das Altas Habilidades/Superdotação (NAAH/S) em todos os estados brasileiros e Distrito Federal. Seus objetivos são: o atendimento educacional especializado aos alunos que possuem altas habilidades/superdotação, a orientação aos familiares desses educandos e a formação continuada de professores. ${ }^{64}$

Em 2008 há a implementação da Política Nacional de Educação Especial na Perspectiva da Educação Inclusiva que trata sobre a temática da inclusão de pessoas com deficiências. Alguns de seus tópicos são: os marcos históricos e normativos, questões históricas relacionadas ao Diagnóstico da Educação Especial, os objetivos da Política Nacional de Educação Especial na Perspectiva da Educação Inclusiva, o público alvo atendido e as Diretrizes da Política Nacional de Educação Especial na Perspectiva da Educação Inclusiva.

${ }^{64}$ Política Nacional de Educação Especial na Perspectiva da Educação Inclusiva, 2008. 


\section{RevistAleph}

A Política Nacional de Educação Especial na Perspectiva da Educação Inclusiva (2008, s/p) tem como objetivo:

[...]assegurar a inclusão escolar de alunos com deficiência, transtornos globais do desenvolvimento e altas habilidades/superdotação, orientando os sistemas de ensino para garantir: acesso ao ensino regular, com participação, aprendizagem e continuidade nos níveis mais elevados do ensino; transversalidade da modalidade de educação especial desde a educação infantil até a educação superior; oferta do atendimento educacional especializado; formação de professores para o atendimento educacional especializado e demais profissionais da educação para a inclusão; participação da família e da comunidade; acessibilidade arquitetônica, nos transportes, nos mobiliários, nas comunicações e informação; e articulação intersetorial na implementação das políticas públicas.

Define ainda a educação especial como "[...] modalidade de ensino que perpassa todos os níveis, etapas e modalidades, realiza o atendimento educacional especializado, disponibiliza os serviços e recursos próprios desse atendimento e orienta os alunos e seus professores quanto à sua utilização nas turmas comuns do ensino regular" (BRASIL, 2008, p/s).

Sobre o Atendimento Educacional Especializado (AEE) este documento o especifica como um serviço que "[...] identifica, elabora e organiza recursos pedagógicos e de acessibilidade que eliminem as barreiras para a plena participação dos alunos, considerando as suas necessidades específicas. [...] Devendo ser ofertado em todas as modalidades da educação básica" (BRASIL, 2008, p/s).

Além disso, a organização do AEE deve ter como finalidade o apoio ao pleno desenvolvimento do aluno, com o planejamento de atividades diferentes das realizadas na sala de aula regular. Sua função é de complemento e/ou suplemento à formação do aluno, visando sua autonomia dentro e fora da escola, com oferta obrigatória pelos sistemas de ensino no contra turno ao do ensino regular, podendo ser feito, de preferência, na escola regular em que o aluno estuda como parte integrante do Projeto Político Pedagógico da instituição ou em locais especializados que ofereçam esse serviço.

Os espaços destinados aos AEE são denominados Sala de Recursos Multifuncionais (SRMF). São espaços físicos dotados de materiais adaptados para o atendimento dos alunos, com 


\section{RevistAleph}

mobiliário, materiais didáticos e pedagógicos, recursos de acessibilidade e equipamentos específicos, que ficam sob a guarda da direção e da comunidade escolar.

Quanto ao público

alvo do AEE estabelece que:

- Alunos com deficiência são aqueles que têm impedimentos de longo prazo, de natureza física, mental, intelectual ou sensorial, que em interação com diversas barreiras podem ter restringida sua participação plena e efetiva na escola e na sociedade;

- Os Transtornos Globais de Desenvolvimento são aqueles que apresentam alterações qualitativas das interações sociais recíprocas e na comunicação, um repertório de interesses e atividades restrito, estereotipado e repetitivo. Incluemse nesse grupo, segundo o documento, alunos do espectro do autismo e psicose infantil;

- Altas habilidades/superdotação são os indivíduos que demonstram potencial elevado em qualquer uma das seguintes áreas, isoladas ou combinadas: intelectual, acadêmica, liderança, psicomotricidade e artes. Também são os que apresentam elevada criatividade, grande envolvimento na aprendizagem e realização de tarefas em áreas de seu interesse.

Em relação às ações presentes na educação superior, o AEE especifica que devem promover o acesso, a permanência e cooperação de todos, por intermédio de recursos de acessibilidade que eliminem as barreiras arquitetônicas, de comunicação dentre outras. 0 documento também faz menção sobre como deve ser realizado o AEE de alunos surdos, sendo na modalidade oral e escrita e na língua de sinais e de alunos cegos por meio do Braille, soroban, orientação e mobilidade. Enfim, atividades que visem à autonomia desses educandos.

De acordo com o artigo $9^{\circ}$ da Resolução CNE/CEB no 4/2009:

A elaboração e a execução do plano de AEE são de competência dos professores que atuam na sala de recursos multifuncionais ou centros de $A E E$, em articulação com os demais professores do ensino regular, com a participação das famílias e em interface com os demais serviços 


\section{RevistAleph}

setoriais da saúde, da assistência social, entre outros necessários ao atendimento.

A institucionalização do AEE no Projeto Político Pedagógico da escola regular e a sua organização estão dispostas na Resolução CNE/CEB no 4/2009, em seu artigo 10․

Quanto à qualificação para atuação no AEE, a Resolução CNE/CEB n‥4/2009 em seu artigo 12 determina que esse profissional tenha formação que o habilite para a docência e formação específica para atuação na educação especial. Sua função é a de realizar o atendimento de maneira complementar ou suplementar à escolarização do aluno, levando em consideração suas especificidades e demandas. Em relação às atribuições destes profissionais, o artigo 13 institui:

I - identificar, elaborar, produzir e organizar serviços, recursos pedagógicos, de acessibilidade e estratégias considerando as necessidades específicas dos alunos público-alvo da Educação Especial;

II - elaborar e executar plano de Atendimento Educacional Especializado, avaliando a funcionalidade e a aplicabilidade dos recursos pedagógicos e de acessibilidade;

III - organizar o tipo e o número de atendimentos aos alunos na sala de recursos multifuncionais;

IV - acompanhar a funcionalidade e a aplicabilidade dos recursos pedagógicos e de acessibilidade na sala de aula comum do ensino regular, bem como em outros ambientes da escola; $\mathrm{V}$ - estabelecer parcerias com as áreas Inter setoriais na elaboração de estratégias e na disponibilização de recursos de acessibilidade; $\mathrm{VI}$-orientar professores e famílias sobre os recursos pedagógicos e de acessibilidade utilizados pelo aluno;

VII - ensinar e usar a tecnologia assistiva de forma a ampliar habilidades funcionais dos alunos, promovendo autonomia e participação;

VIII - estabelecer articulação com os professores da sala de aula comum, visando à disponibilização dos serviços, dos recursos pedagógicos e de acessibilidade e das estratégias que promovem a participação dos alunos nas atividades escolares (BRASIL, 2009, s/p).

Em 2012 foi aprovada a Lei no 12.764, conhecida como "Lei Berenice Piana", em homenagem a uma mãe militante de autista. Essa lei implementa a Política Nacional de Proteção dos Direitos da Pessoa com Transtornos do Espectro do Autismo. Muitos consideram essa lei como sendo o "Estatuto dos Autistas", pois garante o direito à 


\section{RevistAleph}

educação, à saúde, dentre outros, e torna as pessoas com o Transtorno do Espectro do Autismo (TEA) uma pessoa com deficiência, garantindo para esses indivíduos todos os direitos deferidos às pessoas com deficiência.

$\mathrm{O}$ artigo $3^{\circ}$, inciso IV, alínea A desta lei, assegura o acesso "à educação e ao ensino profissionalizante" e garante também o direito em caso de necessidade à acompanhante especializado, quando estiverem incluídos em classes comuns do ensino regular e caso seja comprovada a necessidade.

A Lei no 13.005 de 2014 - cuja vigência é de 10 (dez) anos - intitulada de Plano Nacional de Educação (PNE), determina metas e diretrizes com o intuito de promover o desenvolvimento educacional nas esferas estaduais e municipais. Tem ainda por objetivo em sua meta 4, tornar universal o acesso à educação básica e ao atendimento educacional especializado aos estudantes com deficiência, transtornos globais do desenvolvimento e altas habilidades ou superdotação, preferencialmente na rede regular de ensino, garantindo inclusão nos sistemas educacionais, nas SRMF, dentre outros.

Em 2015 é criada a Lei 13.146 - Lei Brasileira de Inclusão (LBI) também conhecida como o Estatuto da Pessoa com Deficiência, que trouxe vários avanços dos quais destaca-se o direito à educação da pessoa com deficiência. Para tratar dos direitos relacionados à educação, a Lei 13.146 dispõe o Capítulo VI (artigos 27, 28, 29 e 30). O artigo 27 determina a educação como direito da pessoa com deficiência em todos os níveis, estende esse direito ao longo da vida para o desenvolvimento em todas as áreas conforme as suas características e necessidades no âmbito da aprendizagem. Estabelece como dever do Estado, da família, da comunidade escolar e da sociedade garantir a educação de qualidade para seu público alvo.

De acordo com o artigo 28 o poder público deve garantir a criação, desenvolvimento, implementação, acompanhamento e avaliação dos serviços educacionais especializados. Esse artigo, dentre outras coisas, estabelece um sistema educacional inclusivo que deve ocorrer em todos os níveis e modalidades, sendo estendido ao longo da vida e condições de acesso, permanência, participação e aprendizagem, por meio da oferta de serviços e de recursos de acessibilidade que 


\section{RevistAleph}

eliminem as barreiras e promovam a inclusão plena; um projeto político pedagógico que tenha como objetivo atender às características específicas dos estudantes com deficiência ; garante também a oferta de educação bilíngue, em Libras como primeira língua e na modalidade escrita da língua portuguesa como segunda língua, em escolas e classes bilíngues e em escolas inclusivas.

Em resumo, o Atendimento Educacional Especializado, os recursos pedagógicos adaptados, às tecnologias assistivas, a manutenção e ampliação quantitativa das salas de recursos multifuncionais e a especialização dos profissionais da educação se constituem como ferramentas fundamentais para a construção de uma educação inclusiva de pessoas com deficiências.

É de suma importância a elaboração de políticas públicas voltadas para a construção de uma escola enquanto espaço social comum a todos, para que faça valer verdadeiramente o direito à educação de uma maneira universal, pois a educação é um direito de todos e sua oferta é dever do Estado.

\section{Considerações finais}

A educação é assegurada como direito universal de todos desde 1948 com a Declaração Universal dos Direitos Humanos. Em decorrência dela foram estabelecidos documentos em prol da escolarização de pessoas com deficiência. Mantoan (2003, p. 25) evidencia que "os serviços de apoio especializados, tais como os de intérpretes de língua de sinais, aprendizagem do sistema braile e outros recursos especiais de ensino e de aprendizagem, não substituiriam, como ainda ocorre hoje, as funções do professor responsável pela sala de aula da escola comum". Esses estudantes possuem direito a um acompanhante que em algumas literaturas recebe o nome de professor de apoio, (profissional auxiliar de atividades da vida diária - AVDs), e ainda o professor da SRMF, ao realizarem suas atividades no $\mathrm{AEE}$. Os alunos com necessidades educacionais especiais são alunos da escola como os demais e também são alunos do professor regente da turma regular da qual fazem parte. Desta forma, é necessário que haja uma articulação contínua entre esses três professores (professor de apoio, professor regente, professor da SRMF), assim como também entre a família e os profissionais que 


\section{RevistAleph}

os atendem fora da escola - nos serviços clínicos como: psicólogos, fonoaudiólogos entre outros - pois, por intermédio dessa comunicação, será possível elaborar estratégias para o desenvolvimento desses alunos. A escola como um espaço de inclusão deve contar com a cooperação da comunidade na construção do Projeto Político Pedagógico (PPP), e prever adaptações curriculares quando necessárias, metodologias de ensino e os instrumentos avaliativos a serem usados.

As adaptações curriculares também se constituem em ferramentas importantes para auxiliar no desenvolvimento dos estudantes com necessidades educacionais especiais, podem ser realizadas no currículo escolar, em sala de aula e de maneira individual. Os educadores devem ter um olhar e uma escuta sensível com o objetivo de conhecer seus alunos, suas capacidades e potencialidades para formular estratégias que proporcione o pleno desenvolvimento de seus educandos.

Ainda não vivenciamos uma escola inclusiva de fato no Brasil, estamos caminhando para ela. Embora tenhamos leis, normas e documentos que garantam o acesso e a permanência dos alunos público alvo da educação especial, ainda existem algumas barreiras a serem superadas, como os rótulos impostos de "aluno especial", "anormal", "deficiente". Logo, as barreiras a serem quebradas não devem ser apenas arquitetônicas, mas também as atitudinais. Devem ser elaboradas práticas de ensino que contemplem as demandas de todos os alunos com ou sem deficiência e que respeitem a diversidade humana.

Em síntese, é preciso que tenhamos a consciência de que a deficiência não deve ser um rótulo imposto sobre o aluno e que a escola inclusiva e os agentes da educação presentes nessa escola devem agir visando eliminar as barreiras que impeçam o acesso, a permanência e a efetiva aprendizagem de todos os seus alunos.

\section{Referências}

Assembleia Geral da ONU. "Declaração Universal dos Direitos Humanos". "Nações Unidas", 217 (III) A, 1948, Paris, art. 1, Disponível em: < https://www .un.org/en/universal-declarationhuman-rights/>. Acesso em: 15 jul. 2020.

BRASIL. Constituição (1988). Constituição da República Federativa do Brasil de 1988. Brasília, DF: Presidência da República, 2016. Disponível em: < http://www.plana Ito.gov.br/ccivil_03/constituicao/constituicao.htm >. Acesso: 29 jun. 2020. 


\section{RevistAleph}

BRASIL. Decreto no 3.298, de 20 de dezembro de 1999. Regulamenta a Lei $n^{\circ} 7.853$, de 24 de outubro de 1989, dispõe sobre a Política Nacional para a Integração da Pessoa Portadora de Deficiência, consolida as normas de proteção, e dá outras providências. DF, 20 de dez. 1999. Disponível em: < http://www. planalto.go v.br/c ci vil_03/decreto/d3298.htm >. Acesso em: 14 ago. 2020.

BRASIL. Decreto no 5.626, de 22 de dezembro de 2005. Regulamenta a Lei no 10.436, de 24 de abril de 2002, que dispõe sobre a Língua Brasileira de Sinais - Libras, e o art. 18 da Lei no 10.098, de 19 de dezembro de 2000. DF, 22 de dez. 2005. Disponível em: <

http://www.planalto.go v.br/ccivil_03/decreto/d3298.htm >. Acesso em: 10 ago. 2020.

BRASIL. Lei no 4.024, de 20 de dezembro de 1961. Fixa as Diretrizes e Bases da Educação Nacional. Brasília: DF. 1961. Disponível em:< http://www.planalto.gov.br/ccivil_ 03/leis/L4024.htm\#: :text=Fixa\%20as\%20Diretrizes\%20e\%20Bases\%20da\%20Educa\%C3\%A7\% C3\%A3o\%20Nacional.\&text=a)\%20a\%20compreens\%C3\%A30\%20dos\%20direitos,grupos\%20q ue\%20comp\%C3\%B5em\%20a\%20comunidade\%3B\&text=\%C3\%80\%20fam\%C3\%ADlia\%20cabe \%20escolher\%20o,deve\%20dar\%20a\%20seus\%20filhos.>. Acesso em: 10 ago. 2020.

BRASIL. Lei no 7.853, de 24 de outubro de 1989. Dispõe sobre o apoio às pessoas portadoras de deficiência, sua integração social, sobre a Coordenadoria Nacional para Integração da Pessoa Portadora de Deficiência - Corde, institui a tutela jurisdicional de interesses coletivos ou difusos dessas pessoas, disciplina a atuação do Ministério Público, define crimes, e dá outras providências. DF. 1989. Disponível em:< http://www.planalto.gov.br/ccivil_03/leis/L7853. htm>. Acesso em: 14 ago. 2020.

BRASIL. Lei no 8.069, de 13 de julho de 1990. Dispõe sobre o Estatuto da Criança e do Adolescente e dá outras providências. DF, 16 jul. 1990. Disponível em: < http://ww w.planalto.gov.br/ccivil_03/leis/l8069.htm >. Acesso em: 14 ago. 2020.

BRASIL. Lei no 9.394, de 20 de dezembro de 1996. Estabelece as diretrizes e bases da educação nacional. DF, 20 de dez. 1996. Disponível em: < http: //www.planalto. gov.br/ccivil_0 3/leis/l9394.htm>. Acesso em: 14 ago. 2020.

BRASIL. Lei no 10.436, de 24 de abril de 2002. Dispõe sobre a Língua Brasileira de Sinais - Libras e dá outras providências. DF, 20 de abr. 2002. Disponível em: $<$ http://ww w.planalto.gov.br/ccivil_03/leis/l9394.htm>. Acesso em: 14 ago. 2020.

BRASIL. Lei ${ }^{\circ}$ 12.764, de 28 de dezembro de 2012. Institui a Política Nacional de Proteção dos Direitos da Pessoa com Transtorno do Espectro Autista; e altera o § ㅇ do art. 98 da Lei no 8.112, de 11 de dezembro de 1990. DF, 27 de dez. 2012. Disponível em:<https://www.google.com/search?q=12.764\%2F2012\&oq=12.764\%2F2012\&aqs=chrome.. 69i57j6.876j0j7\&sourceid=chrome\&ie=UTF-8>. Acesso em: 14 ago. 2020.

BRASIL. Lei $\mathbf{n}^{\circ} \mathbf{1 3 . 0 0 5}$, de 25 de junho de 2014. Aprova o Plano Nacional de Educação - PNE e dá outras providências, 26 jun. 2014. DF, 25 de jun. 2014. Disponível em: < https://www2.camara.leg.br/legin/fed/lei/2014/lei-13005-25-junho-2014-778970-pu blicacao original-144468-pl.html >. Acesso em: 14 ago. 2020.

BRASIL. Lei $\mathbf{n}^{\circ}$ 13.146, de 6 de julho de 2015. Institui a Lei Brasileira de Inclusão da Pessoa com Deficiência (Estatuto da Pessoa com Deficiência). Brasília, DF, 2015. DF, 06 de jul. 2015. 


\section{RevistAleph}

Disponível em:< http://www.planalto.gov.br/ccivil_03/leis/19394.htm>. Acesso em: 16 ago. 2020.

BRASIL. Ministério da Educação. Documento Orientador do Programa Implantação de Salas de Recursos Multifuncionais. Brasília, DF: Ministério da Educação, [2013?]. Disponível em: < http://portal.mec.gov.br/pnpd/194-secretarias-112877938/secad-educacao-continuada-223 369 541/17430-programa-implantacao-de-salas-de-recurs os-multifuncionais-novo>. Acesso em: 10 de abr. 2019.

BRASIL. Ministério da Educação. Manual de Orientação do Programa de Implantação de Salas de Recursos Multifuncionais. Brasília, DF: Ministério da Educação, 2010. Disponível em: < http://portal.mec.gov.br/pnpd/194-secretarias-112877938/secad-educacao-continuada223369541/17430-programa-implantacao-de-salas-de-recursos-multifuncionais-novo> . Acesso em: 10 de abr. 2019.

BRASIL. Ministério da Educação. Secretaria de Educação Especial. Diretrizes Nacionais para a Educação Especial na Educação Básica. Secretaria de Educação Especial - MEC/SEESP, 2001. Ministério da Educação. Secretaria de Educação Especial. Grafia Braille para a Língua Portuguesa / elaboração: Cerqueira, Jonir Bechara... [et al.]. Secretaria de Educação Especial. Brasília: SEESP, 2006. 106p.

BRASIL. Ministério da Educação. Secretaria de Educação Especial. Política Nacional de Educação Especial na Perspectiva da Educação Inclusiva (2008). Disponível em: <http://portal.mec. gov.br/arquivos/ pdf/politicaeducespecial.pdf>. Acesso: 10 ago. 2020.

BRASIL. Resolução no. 4, de 2 de outubro de 2009. Diretrizes Operacionais para o Atendimento Educacional Especializado na Educação Básica, modalidade Educação especial, Brasília: MEC, 2009.

BRASIL. Resolução no. 4, de 13 de julho de 2010. Define Diretrizes Curriculares Nacionais Gerais para a Educação Básica, Brasília: MEC, 2010.

CABRAL, L. S. A.. Educação Especial: histórico, políticas e práticas. Ebook. [S.I.]

MANTOAN, Maria Tereza Eglér. Inclusão Escolar: O que é? Por quê? Como fazer? São Paulo: Moderna, 2003

MAZZOTTA, M.J. da S.; SOUSA, S.M. Z. L. Inclusão escolar e educação especial: considerações sobre a política educacional brasileira. Estilos clin., São Paulo, v. 5, n. 9, p. 96-108, 2000

. Disponível em <http://pepsic.bvsa lud.org/scielo. php?script=sci_Zarttext\&pid=S1 $41571282000000200007 \&$ Ing=p t\&nrm=iso>. Acesso em: 28 jul. 2020.

MAZZOTTA, M.J. da S.. Reflexões sobre inclusão com responsabilidade. Revista @mbienteeducação, [S.I.], v. 1, n. 2, abr. 2008. ISSN 1982-8632. Disponível em: $<$ http://publicacoe s.unicid.edu.br/index.p hp/ambiente educacao/article/vie w/598/562>. Acesso em: 28 jul. 2020.

MAZZOTTA, M. J. da S.; D'ANTINO, M. E.F.. Inclusão social de pessoas com deficiências e necessidades especiais: cultura, educação e lazer. Saúde soc., São Paulo , v. 20, n. 2, p. 377389, June 2011 . Disponível: <http://www.scielo 


\section{RevistAleph}

.br/scielo.php?script=sci_arttext\&pid=S0104-12902011000200010\&lng=en\&nrm=iso $>$. Acesso em : 30 Jul. 2020.

MENEZES, J. E. S. A. de. Língua Brasileira de Sinais (LIBRAS) / Jane Eire Silva Alencar de Menezes e Cléia Rocha de Sousa Feitosa. - 2. ed. rev. - Fortaleza : EdUECE, 2015. 150 p. : il.

MORAES, L.. A educação especial no contexto do Plano Nacional de Educação / Louise Moraes. - Brasília, DF : Instituto Nacional de Estudos e Pesquisas Educacionais Anísio Teixeira, 2017.42 p.

ORTEGA, F.. Deficiência, autismo e neurodiversidade. Ciênc. saúde coletiva, Rio de Janeiro, v. 14, n. 1, p. 67-77, fevereiro de 2009. Disponível em http://www. Sciel o.br/scielo.php?script=sci_arttext\&pid=S1413-81232009000100012\&lng=em \&n r=isso . Acesso em: 28 abr. 2020.

RIOS, C.. "Nada sobre nós, sem nós"? O corpo na construção do autista como sujeito social e político. Sex., Salud Soc. (Rio J.) , Rio de Janeiro, n. 25, p. 212-230, abril de 2017. Disponível em <http://www.scielo.br/scielo.php?script=sci_artte xt\&pid=S1984-6487201700010021 2 \&lng=en\&nrm=iso >. Acesso em: 28 abr. 2020.

SILVA, A. J. da D. Os direitos das pessoas com deficiência - ênfase em autismo: uma tabela de direitos, textos legais e casos de jurisprudência. / Organizador: Alexandre José da Silva - São Leopoldo: Oikos , 2012. 56 p.; 21 x 29,7 cm. - (Cadernos Pandorga de Autismo, v. 4)

SASSAKI, R. K. Terminologia sobre a deficiência na era da inclusão. In: VIVARTA, V. (Org.) Mídia e Deficiência. Brasília: Andi; Fundação Banco do Brasil, 2003. p. 160-165.

SASSAKI, R. K.. Como chamar as pessoas que têm deficiência? Diversa educação inclusiva na prática. 13 mar. 2014. Disponivel em: <https://diversa.org.br/artigos/como-chamar-pessoasque-tem-deficiencia/>. Acesso em : 10 ago. 2020.

SILVA, A. J. da D., Cidadania e pessoas com deficiência. São Leopoldo: Oikos, 2012.72 p.; 16 x $23 \mathrm{~cm}$. - Cadernos Pandorga de Autismo, v. 3.

UNESCO. Declaração de Salamanca. Sobre Princípios, Políticas e Práticas na Área das Necessidades Educativas Especiais. Disponível em: <http://por tal.m ec.gov .br/see sp/arquivo s/pdf/salamanca.pdf> Acesso em: 11 ago. 2020.

UNICEF. Declaração Mundial sobre Educação para Todos. UNESCO, 1990. Disponível em < https://www.unicef.org/brazil/declaracao-mundial-sobre-educacao-para-todos-conferenciade-jomtien-1990 >. Acesso em: 10 ago. 2020. 